\title{
AULA PRATICA DE VÍRUS E BACTÉRIAS NO ENSINO FUNDAMENTAL
}

\section{Teresa de Araújo Oliveira Medeiros ${ }^{1}$ \\ Daphne Alves Dias ${ }^{2}$ \\ Jéssika Santos de Oliveira ${ }^{3}$ \\ Maria Juliana Araújo de Oliveira ${ }^{4}$}

Resumo: O uso de metodologias para o ensino de Ciências tem se modernizado a cada dia em busca de melhor compreensão do aluno e conexão do ensino teórico com sua aplicação na prática. Com isso, professores tem lançado mão de aulas práticas mais dinâmicas e investigativas, despertando o interesse de seus alunos. O objetivo do trabalho é contribuir para a aprendizagem dos conteúdos de vírus e bactérias, por meio de aulas práticas investigativas. A metodologia utilizada foi a separação de duas turmas $A$ e $B$, com 24 e 19 alunos respectivamente, totalizando 43 alunos. Cada turma realizou a observação das bactérias do iogurte ao microscópio, respondendo ao questionário aplicado, em seguida, cada turma realizou a montagem de modelos de bactérias e vírus. As turmas demonstraram interesse e empolgação para a realização de atividades, assim como capacidade em responder questionamentos.

Palavras-chave: Aprendizagem; Ensino Ciências; Educação; Microscópio.

\footnotetext{
1 Licenciatura em Ciências Biológicas/Instituto Federal do Espirito Santo/Campus Alegre, Brasil. E-mail: teresa_a.oliveira@hotmail.com.

2 Licenciatura em Ciências Biológicas/Instituto Federal do Espirito Santo/Campus Alegre, Brasil. E-mail: daph.alves@gmail.com.

3 Licenciatura em Ciências Biológicas/Instituto Federal do Espirito Santo/Campus Alegre, Brasil. E-mail: jessikaoliveira664@gmail.com.

4 Licenciado em Ciências Biológicas/Instituto Federal do Espirito Santo/Campus Alegre, Brasil. E-mail: ju.oliveira41@hotmail.com.
} 